\title{
The expanding scope of psychiatric epidemiology in the 21st century
}

\author{
Katherine M. Keyes • Ezra Susser
}

Received: 8 July 2014 / Accepted: 16 July 2014/Published online: 6 August 2014

(C) Springer-Verlag Berlin Heidelberg 2014

The series of reviews commissioned by SPPE over the past year shed important insights on the current state of psychiatric epidemiology [1-5]. Our reading of this series has led us into discussions of the scope and goals of our discipline, and how, within a historical context, it is expanding in both predicted and unforeseen ways. In this editorial we first reflect on the history of our field, and how the wealth of information in these reviews provides insight into newly emerging directions of inquiry. Then we discuss major advances and remaining challenges in the field not covered in the series. Finally, we consider the overall scope and future directions of psychiatric epidemiologic inquiry in the years to come.

Scholars have consistently sought to define the major questions and challenges of our field. With respect to studies of the prevalence of mental disorders in the community, Bruce and Barbara Dohrenwend marked three generations: pre-World War II, post-World War II, and the third generation beginning around 1980 with the publication of DSM-III and with it a consistent set of criteria to measure psychiatric disorder prevalence [6, 7]. More recently, for detecting causes, we [8-10] as well as others $[11,12]$ called for adopting the methods of mainstream epidemiology (with modifications) for the study of risk factors, as well as for studying causes at multiple levels using frameworks such as eco-epidemiology. The reviews in this series indicate that these frameworks have been

K. M. Keyes $(\bowtie) \cdot$ E. Susser

Department of Epidemiology, Mailman School of Public Health, Columbia University, New York, NY, USA

e-mail: kmk2104@columbia.edu

E. Susser

New York State Psychiatric Institute, New York, NY, USA adopted in exciting ways, but that advances in the field have also generated unforeseen but productive questions, methods, and lines of inquiry as well.

Collectively, the SPPE reviews indicate that among the many advances in our field right now is a focused pursuit in understanding the mechanisms through which social forces and relationships become embodied in biological processes to produce adverse mental health consequences. The pervasive ways in which our environments affect our health and behavior have long been a hallmark of our field, and yet information and questions take new and exciting shape as we learn more about the interplay between the biological and social. As the two SPPE reviews on gene by environment interactions demonstrate [2, 4], our understanding of the complexity underlying the genetic architecture of many disorders is rapidly advancing. As a field we have shifted attention from the identification of specific polymorphisms that potentiate psychiatric outcomes, to debate and development of more nuanced and complex methods to understand these architectures. The panorama of psychiatric genetics continues to shift as we learn and advance evermore, and technology becomes increasingly sophisticated. Such advance will be aided by the integration of genetic and biological measures into community-based epidemiological studies, which is slowly but steadily increasing.

Of course, novel information brings new challenges and opportunities. Notably, given that most genetic effects are modified by environmental processes, it is ever more urgent to focus attention on rich and diverse environmental assessments, as discussed by Uher as well as Iyegbe et al. $[2,4]$. As globally focused studies become more feasible, they will advance such assessment, as environmental variation within particular geographically located populations (for example, the focus of research on high-income 
countries) may not be sufficient to fully capture the enormous variation in environmental exposures worldwide. Further, while polygenetic scores such as those reviewed by Iyegbe et al. [2] remain in early stages of development, genomic studies have revealed large effects of individually rare mutations that run across neurodevelopmental disorders $[13,14]$, some of which are de novo mutations. Taken together, there is much to be done in the field but many exciting advances to provide the foundation for new research avenues.

Our increasing ability to understand social mechanisms is also exciting, as it brings the long-standing tradition in psychiatric epidemiology of elucidating the impact of the social environment on health to a new level. In this series we have read reviews of epigenetic [5], inflammatory [1], psychological, and neurobiological [3] routes through which stress, adversity, maltreatment, and other key social exposures of interest may adversely influence mental health and distress. The wealth of accumulating information is invigorating, and our ability to understand the pathways through which social exposures and stressful experiences influence mental health has implications for developing the ability to modify these processes and prevent disorder from occurring. However, much of this research remains in its infancy. The field of epigenetic research has generated enormous excitement and enthusiasm that we may now be able to better understand the biological mechanisms by which the social environment so pervasively affects health [15], yet methodological challenges have limited the extent to which research in human populations is generating substantial insights [16]. Similarly, new technology in neuroimaging and other neurobiological techniques have exponentially increased the scientific literature about how disorders manifest in the brain [17], but the methods remain in development. The history of our field is long and rich with a commitment to understanding how social factors, including societal factors, familial relationships, and adversity shape mental health and wellbeing [7, 18, 19].

The new tools, collaboration, and information hold promise for our ability to dramatically increase our understanding of etiology, but this potential has not yet, for the most part, been realized. Rather, it is humbling that perhaps what we have learned most is that the etiology of most psychiatric disorders is more complex that we envisioned even a decade ago. In that way, the current scope of psychiatric epidemiology can be viewed as having a foundation laid by the work of the last century and the theoretical models of the past 20 years, integrating new scientific complexities and shifting our frames to incorporate new discoveries [20].

It is critical to note, however, that innovation in our field is not limited to advances in biological and genetic psychiatry as described in these reviews. Global mental health has, in the past 10 years, become a major area of epidemiologic research, which was largely unforeseen at the turn of the century. This focus on understanding the drivers of and interventions to reduce the burden of mental disorders worldwide has the potential to be transformational for the field, as increasingly all health, including mental health, is being conceptualized as a human right that requires global commitment and resources mobilized in international collaborations [21]. Further, we are developing massive and well-designed international data resources, with longitudinal registries of populations. As one of many possible examples, the iCare study was recently initiated to examine risk factors and trends in autism combining a host of complex registries and data systems in seven different countries [22]. There has been a proliferation of multi-level and multi-national studies, and we are beginning to execute global and multi-generational studies as well. Though comparisons remain observational in nature, these large studies confirm the critical role of social factors in the production of mental health outcomes. We have also begun to better understand factors that are at least in part socially determined or manifestations of social processes, and that have direct implications for testing mechanisms, such as father's age at conception [23] and prenatal malnutrition [24].

There remain additional challenges to the field that were covered in less detail in the review series. First, the debate over the reliability and validity of our measures of mental illness continues to be a major source of contention in the field. With the publication of the new version of the DSM this year came a renewed focus on what we mean by psychiatric disorders, and how best to measure them. The National Institute of Mental Health and others have encouraged a shift of focus away from traditionally defined categorical definitions of psychiatric disorders toward an approach that corresponds better with what we are beginning to learn about their underlying pathophysiology [25, 26]. Debates over measurement are non-trivial, as they have major implications for all stakeholders, including researchers, public health practitioners, clinicians, insurers, and consumers. Second, understanding the evolution of psychiatric disorders over the life course remains a critical aspect of the field, given what we have learned about the early origins, from fetal development to childhood, of many psychiatric disorders. At the other end of the life course, the demographics of the world population has shifted in the past several decades, and we can portend a large increase in the proportion of the population that is over 65 . Research on mental health during the aging process is underserved and critical. Third, there is renewed awareness and interest in defining and studying positive mental 
health and wellbeing [27], which is an important area for public health focus.

Fourth, while there is undeniably an increase in our potential ability to accomplish new scientific goals, the translation of the findings into public health and clinical improvements, on a global scale, remains to be demonstrated. There are reasons, however, to be optimistic. Genomic medicine is advancing, elucidation of the neurobiology of behavior is fielding many new hypotheses about clinical translation [28], and the availability of large data resources will likely enhance this effort. The advance of the global mental health movement is creating the capacity to apply not only current but also future advances outside the context of the high-income countries which comprise only a minority of the world's population. The major mental health burden currently being experienced globally [29] is receiving increasing attention [30]. Thomas Insel recently wrote that the recent World Economic Forum in Davos, Switzerland included an "unprecedented" focus on improving mental health worldwide, and extended the commonly used phrase "no health without mental health" to "no wealth without mental health" [31], due to the high medical costs and loss of productivity claimed by mental illness. While the identification and quantification of risk factors for mental illness is a cornerstone of psychiatric epidemiology, more public health 'wins' in reducing the burden of mental illness are urgently needed. Within this context, it is worth emphasizing that psychiatric epidemiologists must be vigilant towards pursuing a research program of consequence to those most marginalized. As such, a greater focus on identification, treatment and social justice for individuals with psychiatric disorders must remain at the forefront of our mission as public health researchers.

Taken together, how do we conceptualize the scope of our field, and is it shifting? This question remains to be answered in the fullness of time, but there are several reasons to think that our scope as a field is expanding and becoming increasingly integrated with other areas of epidemiology and public health. The SPPE reviews illustrate one part of that shift, including that we now have the potential to focus on the mechanisms through which social factors penetrate. We have improved our ability to test biological mechanisms underlying our epidemiologically observed associations between environmental factors and psychiatric disorders. More broadly, the field is increasingly designing and executing studies that are globally focused, multilevel, and multigenerational. These changes perhaps illustrate the shifts necessary in the field that have been called for within the past several decades, but also reflect new and interesting findings and methods that have been developed.
In summary, as described in this series of reviews, the scientific and methodological advances in our understanding of psychiatric health are promising. We are learning about the complexity of the genetic architecture underlying psychiatric disorders, the neural mechanisms through which disorders occur and affect mood and behavior, and the ways in which social and environmental conditions influence health in both positive and negative ways. At the same time, of course, is the need for capacity building to treat psychiatric disorders globally $[32,33]$. The expansion of psychiatric epidemiology to low- and middle-income countries has the potential to be transformative, especially coupled with the ability to work multi-disciplinarily combining experts in the social and cultural conditions through which mental illness arises along with neuroscientific advances in our understanding of mechanism. These efforts more than all others have the potential to reshape the population burden of mental illness, leading potentially to a new and productive generation of our field. As we move forward, an eye toward continuing to advance many of the challenges our field still faces, as well as always remaining vigilant to the need for translation of our work into improved population health [34], will provide the necessary foundations to ensure that our studies truly have consequence for both understanding psychiatric disorders and improving the lives of those around the world who continue to suffer with illness and distress.

\section{Conflict of interest None.}

\section{References}

1. Baumeister D, Russell A, Pariante CM, Mondelli V (2014) Inflammatory biomarker profiles of mental disorders and their relation to clinical, social and lifestyle factors. Soc Psychiatry Psychiatr Epidemiol 49(6):841-849

2. Iyegbe C, Campbell D, Butler A, Ajnakina O, Sham P (2014) The emerging molecular architecture of schizophrenia, polygenic risk scores and the clinical implications for GxE research. Soc Psychiatry Psychiatr Epidemiol 49(2):169-182. doi:10.1007/s00127014-0823-2

3. Akdeniz C, Tost H, Meyer-Lindenberg A (2014) The neurobiology of social environmental risk for schizophrenia: an evolving research field. Soc Psychiatry Psychiatr Epidemiol 49:507-517

4. Uher R (2014) Gene-environment interactions in common mental disorders: an update and strategy for a genome-wide search. Soc Psychiatry Psychiatr Epidemiol 49(1):3-14. doi:10.1007/s00127013-0801-0

5. Pishva E, Kenis G, van den Hove D, Lesch KP, Boks MP, van Os J, Rutten BP (2014) The epigenome and postnatal environmental influences in psychotic disorders. Soc Psychiatry Psychiatr Epidemiol 49(3):337-348. doi:10.1007/s00127-014-0831-2

6. Dohrenwend BP (1990) 'The problem of validity in field studies of psychological disorders' revisited. Psychol Med 20(1): 195-208 
7. Dohrenwend BP, Dohrenwend BS (1982) Perspectives on the past and future of psychiatric epidemiology. The 1981 Rema Lapouse Lecture. Am J Public Health 72(11):1271-1279

8. March D, Susser E (2006) The eco- in eco-epidemiology. Int J Epidemiol 35(6):1379-1383. doi:10.1093/ije/dyl249

9. Susser M, Susser E (1996) Choosing a future for epidemiology: II. From black box to Chinese boxes and eco-epidemiology. Am J Public Health 86(5):674-677

10. Susser E, Schwartz S, Morabia A, Bromet EJ (2006) Psychiatric epidemiology: searching for the causes of mental disorders. Oxford University Press, New York

11. Cooper B (2014) Epidemiology in a changing world: implications for population-based research on mental disorders. Epidemiol Psychiatr Sci 23(2):141-146. doi:10.1017/S2045796013000644

12. Brown AS, McGrath JJ (2011) The prevention of schizophrenia. Schizophr Bull 37(2):257-261. doi:10.1093/schbul/sbq122

13. Fromer M, Pocklington AJ, Kavanagh DH, Williams HJ, Dwyer S, Gormley P, Georgieva L, Rees E, Palta P, Ruderfer DM, Carrera N, Humphreys I, Johnson JS, Roussos P, Barker DD, Banks E, Milanova V, Grant SG, Hannon E, Rose SA, Chambert K, Mahajan M, Scolnick EM, Moran JL, Kirov G, Palotie A, McCarroll SA, Holmans P, Sklar P, Owen MJ, Purcell SM, O'Donovan MC (2014) De novo mutations in schizophrenia implicate synaptic networks. Nature. doi:10.1038/nature12929

14. Lehner T, Senthil G, Addington AM (2014) Convergence of advances in genomics, team science, and repositories as drivers of progress in psychiatric genomics. Biol Psychiatry. doi:10.1016/j. biopsych.2014.01.003

15. Champagne FA (2012) Interplay between social experiences and the genome: epigenetic consequences for behavior. Adv Genet 77:33-57. doi:10.1016/B978-0-12-387687-4.00002-7

16. Mill J, Heijmans BT (2013) From promises to practical strategies in epigenetic epidemiology. Nat Rev Genet 14(8):585-594. doi:10.1038/nrg3405

17. Krabbendam L, Hooker CI, Aleman A (2014) Neural effects of the social environment. Schizophr Bull. doi:10.1093/schbul/ sbt233

18. Dohrenwend BP (1998) A psychosocial perspective on the past and future of psychiatric epidemiology. Am $\mathrm{J}$ Epidemiol 147(3):222-231

19. Schwartz S, Diez Roux AV, Susser E (2006) Causal explanations outside the black box. In: Susser E, Schwartz S, Morabia A, Bromet EJ (eds) Psychiatric epidemiology: searching for the causes of mental disorders. Oxford University Press, New York

20. Weissman M, Brown AS, Talati A (2014) Translational Epidemiology in psychiatry: linking population to clinical and basic sciences. Arch Gen Psychiatry 68(6):600-608

21. Susser E, Patel V (2014) Psychiatric epidemiology and global mental health: joining forces. Int J Epidemiol 43(2):287-293. doi:10.1093/ije/dyu053

22. Schendel DE, Bresnahan M, Carter KW, Francis RW, Gissler M, Gronborg TK, Gross R, Gunnes N, Hornig M, Hultman CM, Langridge A, Lauritsen MB, Leonard H, Parner ET, Reichenberg A, Sandin S, Sourander A, Stoltenberg C, Suominen A, Suren P,
Susser E (2013) The international collaboration for autism registry epidemiology (iCARE): multinational registry-based investigations of autism risk factors and trends. J Autism Dev Disord 43(11):2650-2663. doi:10.1007/s10803-013-1815-x

23. D'Onofrio BM, Rickert ME, Frans E, Kuja-Halkola R, Almqvist C, Sjolander A, Larsson H, Lichtenstein P (2014) Paternal age at childbearing and offspring psychiatric and academic morbidity. JAMA Psychiatry 71(4):432-438. doi:10.1001/jamapsychiatry. 2013.4525

24. Susser E, St Clair D (2013) Prenatal famine and adult mental illness: interpreting concordant and discordant results from the Dutch and Chinese Famines. Soc Sci Med 97:325-330. doi:10. 1016/j.socscimed.2013.02.049

25. Cuthbert BN (2014) The RDoC framework: facilitating transition from ICD/DSM to dimensional approaches that integrate neuroscience and psychopathology. World Psychiatry 13(1):28-35. doi: $10.1002 /$ wps. 20087

26. Insel T, Cuthbert B, Garvey M, Heinssen R, Pine DS, Quinn K, Sanislow C, Wang P (2010) Research domain criteria (RDoC): toward a new classification framework for research on mental disorders. Am J Psychiatry 167(7):748-751. doi:10.1176/appi. ajp.2010.09091379

27. Vaillant GE (2012) Positive mental health: is there a cross-cultural definition? World Psychiatry 11(2):93-99

28. Insel TR, Voon V, Nye JS, Brown VJ, Altevogt BM, Bullmore ET, Goodwin GM, Howard RJ, Kupfer DJ, Malloch G, Marston HM, Nutt DJ, Robbins TW, Stahl SM, Tricklebank MD, Williams JH, Sahakian BJ (2013) Innovative solutions to novel drug development in mental health. Neurosci Biobehav Rev 37(10 Pt 1):2438-2444. doi:10.1016/j.neubiorev.2013.03.022

29. Whiteford HA, Degenhardt L, Rehm J, Baxter AJ, Ferrari AJ, Erskine HE, Charlson FJ, Norman RE, Flaxman AD, Johns N, Burstein R, Murray CJ, Vos T (2013) Global burden of disease attributable to mental and substance use disorders: findings from the Global Burden of Disease Study 2010. Lancet 382(9904):1575-1586. doi:10.1016/S0140-6736(13)61611-6

30. Becker AE, Kleinman A (2013) Mental health and the global agenda. N Engl J Med 369(1):66-73. doi:10.1056/NEJMra 1110827

31. Insel T (2014) Mental health in Davos. Director's Blog: http:// www.nimh.nih.gov/about/director/2014/mental-health-in-davos. shtml

32. Patel V, Araya R, Chatterjee S, Chisholm D, Cohen A, De Silva M, Hosman C, McGuire H, Rojas G, van Ommeren M (2007) Treatment and prevention of mental disorders in low-income and middle-income countries. Lancet 370(9591):991-1005. doi:10. 1016/S0140-6736(07)61240-9

33. Patel V, Saxena S (2014) Transforming lives, enhancing communities-innovations in global mental health. $\mathrm{N}$ Engl $\mathrm{J}$ Med 370(6):498-501. doi:10.1056/NEJMp1315214

34. Galea S (2013) An argument for a consequentialist epidemiology. Am J Epidemiol 178(8):1185-1191. doi:10.1093/aje/kwt172 